\section{A transient liquid-like phase in the displacement cascades of zircon, hafnon and thorite}

\author{
A. Meldrum ${ }^{\star}$, S. J. Zinkle $\dagger$, L. A. Boatner ${ }^{\star}$ \& R. C. Ewing $\ddagger$ \\ * Oak Ridge National Laboratory, Solid State Division, Oak Ridge, \\ Tennessee 37831-6057, USA \\ $\dagger$ Oak Ridge National Laboratory, Metals and Ceramics Division, Oak Ridge, \\ Tennessee 37831-6376, USA \\ $\$$ The University of Michigan, Department of Nuclear Engineering and \\ Radiological Sciences and the Department of Geological Sciences, Ann Arbor, \\ Michigan 48109-2104, USA
}

The study of radiation effects in solids is important for the development of 'radiation-resistant' materials for fission-reactor applications ${ }^{1}$. The effects of heavy-ion irradiation in the isostructural orthosilicates zircon $\left(\mathrm{ZrSiO}_{4}\right)$, hafnon $\left(\mathrm{HfSiO}_{4}\right)$ and thorite $\left(\mathrm{ThSiO}_{4}\right)$ are particularly important because these minerals are under active investigation for use as a waste form for plutonium239 resulting from the dismantling of nuclear weapons ${ }^{2-4}$. During ion irradiation, localized 'cascades' of displaced atoms can form as a result of ballistic collisions in the target material, and the temperature inside these regions may for a short time exceed the bulk melting temperature. Whether these cascades do indeed generate a localized liquid state ${ }^{5-8}$ has, however, remained unclear. Here we investigate the irradiation-induced decomposition of zircon and hafnon, and find evidence for formation of a liquidlike state in the displacement cascades. Our results explain the frequent occurrence of $\mathrm{ZrO}_{2}$ in natural amorphous zircon ${ }^{9-12}$. Moreover, we conclude that zircon-based nuclear waste forms should be maintained within strict temperature limits, to avoid potentially detrimental irradiation-induced amorphization or phase decomposition of the zircon.

Zircon is a commonly occurring accessory mineral found in a wide variety of rock types that typically contains 5-4,000 p.p.m. uranium and up to 2,000 p.p.m. thorium. It has been synthesized with up to $10 \mathrm{wt} \%$ plutonium (ref. 13), and pure $\mathrm{PuSiO}_{4}$ has the tetragonal zircon structure ${ }^{14}$. Most natural zircons contain less than $3 \mathrm{~mol} \%$ hafnium, and the average $\mathrm{Zr}: \mathrm{Hf}$ ratio in zircon is $40: 1-\mathrm{a}$ value which corresponds to the natural abundance of these elements in the Earth's crust. However, hafnon grains with up to $97 \mathrm{~mol} \% \mathrm{Hf}$ have been reported ${ }^{15}$ (with the remaining 3\% being $\mathrm{Zr}$ ), and zircon forms a complete solid solution with hafnon. The actinide-bearing

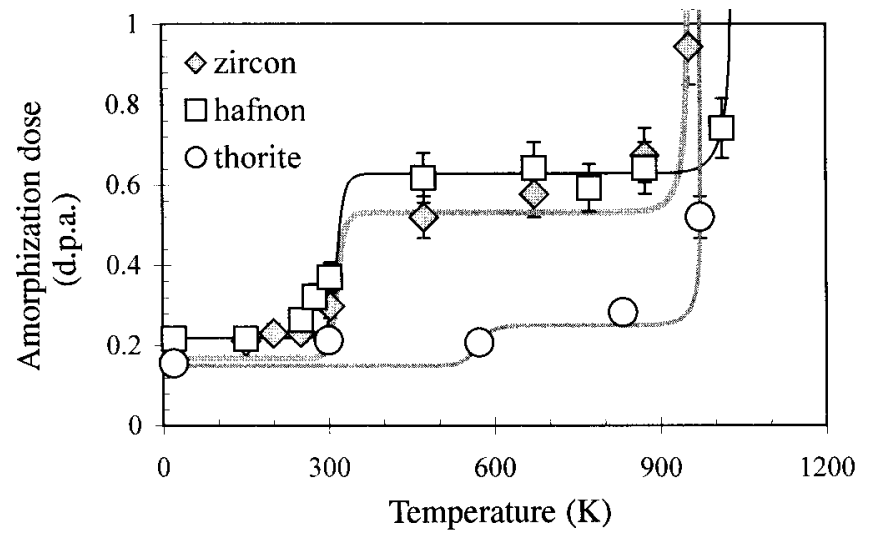

Figure 1 Critical amorphization dose as a function of temperature for zircon, hafnon and thorite. The error bars are 10\%, and the lines were obtained by solving an amorphization/recrystallization model which we have developed ${ }^{20}$. Ion irradiations were performed at the HVEM-Tandem Facility at Argonne National Laboratory using a flux of $1.7 \times 10^{12}$ ions $\mathrm{cm}^{-2} \mathrm{~s}^{-1}$ mineral thorite $\left(\mathrm{ThSiO}_{4}\right)$ is isostructural with zircon and, like zircon, is frequently found to be metamict (amorphous). The lack of intermediate compositions between zircon and thorite suggests a relatively wide miscibility gap ${ }^{16}$.

Pure, synthetic zircon, hafnon and thorite crystals were irradiated with $800-\mathrm{keV} \mathrm{Kr}^{+}$ions in situ in a transmission electron microscope. All of the materials were amorphized at temperatures up to $900 \mathrm{~K}$. The fluence was converted to displacements per atom (d.p.a.) through TRIM-96 ${ }^{17}$ calculations using atomic displacement energy values of $79 \mathrm{eV}(\mathrm{Zr}), 23 \mathrm{eV}(\mathrm{Si})$ and $47 \mathrm{eV}(\mathrm{O})$ recently estimated for $\operatorname{zircon}^{18}$. At low doses, disordered regions $\sim 3 \mathrm{~nm}$ in diameter, corresponding to individual damage cascades, were observed by high-resolution microscopy. At higher doses, the materials gradually became amorphous, as determined by electron-diffraction. The amorphization dose $\left(D_{c}\right)$ was observed to increase in two stages as a function of temperature (Fig. 1), consistent with previous experiments on $\operatorname{zircon}^{13}$ and $\alpha$-alumina ${ }^{19}$.

The temperature dependence of the amorphization dose can be modelled by assuming that the effect of temperature is to cause continuous recrystallization at the cascade boundaries ${ }^{20}$. For the orthosilicates, the activation energies for irradiation-enhanced recrystallization are $3-3.6 \mathrm{eV}$. These high values explain why natural specimens of orthosilicates are frequently found to be metamict. In comparison, we have found that the activation energies for the almost invariably crystalline radionuclide-bearing minerals monazite $\left(\mathrm{CePO}_{4}\right)$ and apatite $\left(\mathrm{Ca}_{5}\left(\mathrm{PO}_{4}\right)_{3} \mathrm{~F}\right)$ are lower by a factor of nearly 3 . Using these activation energies for the orthosilicates, a minimum temperature of $\sim 700 \mathrm{~K}$ is required to ensure the longterm crystallinity of a $\mathrm{Pu}$-loaded zircon waste form.

On increasing the temperature to $950 \mathrm{~K}$ (zircon) and $\sim 1,000 \mathrm{~K}$ (hafnon), a new effect was observed. Above these temperatures, the material decomposed under irradiation into the component oxides: tetragonal $\mathrm{ZrO}_{2}$ or $\mathrm{HfO}_{2}+$ amorphous $\mathrm{SiO}_{2}$. The development of these new phases was determined by electron diffraction (Fig. 2). At $300 \mathrm{~K}$, zircon was amorphized at 0.3 d.p.a. but at $1,050 \mathrm{~K}$ zircon and hafnon decomposed directly into their component oxides. In contrast, $\mathrm{ThO}_{2}$ did not precipitate in the displacement cascades of crystalline thorite at these temperatures. High-resolution electron microscopy confirmed the presence of nanocrystalline $\mathrm{ZrO}_{2}$ and $\mathrm{HfO}_{2}$ in the zircon and hafnon specimens (Fig. 3). The observed crystallite size is comparable to the cascade dimensions.

Specimens amorphized at low temperatures were also heated above the temperature at which the radiation-induced phase
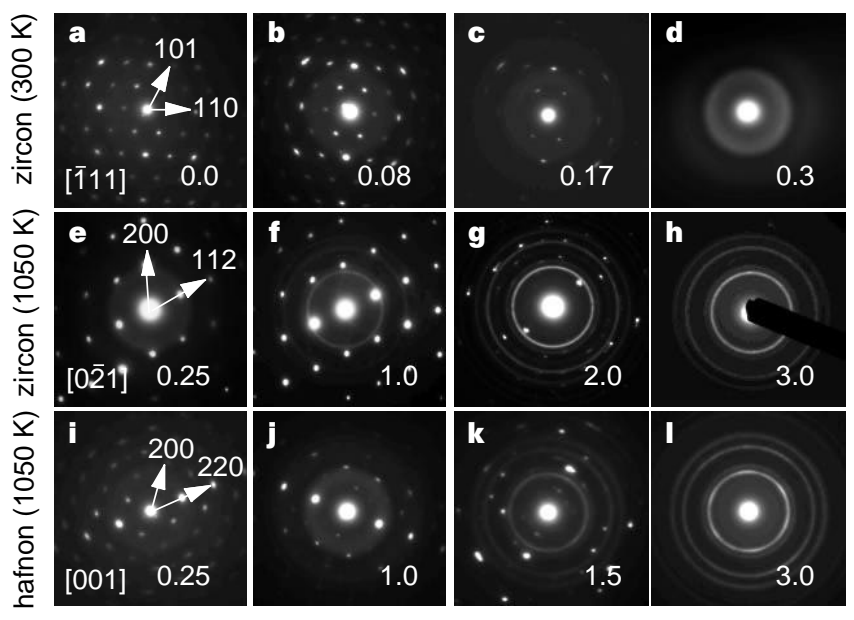

Figure 2 Sequences of electron-diffraction patterns documenting the effects of ion irradiation at different temperatures. a-d, Zircon at $300 \mathrm{~K}$; $\mathbf{e - h}$, zircon at $1,050 \mathrm{~K}$; and $\mathbf{i}-\mathbf{I}$, hafnon at 1,050 K. At high temperatures, the gradual development of diffraction 'rings' marked the onset of the phase decomposition. The dose in d.p.a. is given at the bottom right of each diffraction pattern. The arrows point to higher-order spots. 
decomposition was observed and held for 20 minutes to determine if the formation of the component oxides was thermally induced. Phase decomposition did not occur in any of the specimens amorphized at low temperature and then held at $1,100 \mathrm{~K}$ for 20 minutes. However, when the ion beam was then allowed to impinge on the amorphous specimens, rapid formation of crystalline $\mathrm{ZrO}_{2}$ and $\mathrm{HfO}_{2}$ was observed. The component oxide phases did not redissolve when held for 60 minutes at $1,100 \mathrm{~K}$. Specimen heating caused by the ion beam was quantified by irradiating specimens of the ferroelectric phase-change material $\mathrm{KNbO}_{3}$ under identical conditions and was found to be less than $30 \mathrm{~K}$.

These experiments show that the phase decomposition of zircon and hafnon into their component oxides is nucleated through the effects of the ion irradiation. This has important ramifications in situations where these materials may be exposed to irradiation, particularly at elevated temperatures. For example, the present results imply that a $\mathrm{Pu}$-loaded zircon waste form should be maintained at temperatures well below the phase decomposition temperature in order to avoid the redistribution of $\mathrm{Pu}$ and its daughter products between the component oxides. On the basis of these results and on the model derived to plot the lines in Fig. 1, there is a temperature 'window' between approximately 700 and $900 \mathrm{~K}$ in which a $\mathrm{Pu}$-doped zircon waste form will neither amorphize nor undergo phase decomposition.

A convincing explanation for the presence of crystalline precipitates at high irradiation temperatures in the displacement cascades of zircon and hafnon and their absence in thorite can be based on the 'thermal spike' model. Recent molecular dynamics simulations suggest that collision cascades have two main stages: an initial ballistic stage during which many atoms are dislodged from their lattice sites, and a subsequent thermal spike phase in which the cascade region attains thermal equilibrium with its surroundings $^{6,21,22}$. During the thermal spike, the atoms inside the displacement cascade may achieve a liquid-like state (cascade melting), a phenomenon that is of general interest for both fundamental condensed-matter physics and applied technologies such as the ion-beam processing of semiconductors. However, there has been little experimental evidence to substantiate these predictions.

From an examination of the published $\mathrm{ZrO}_{2}-\mathrm{SiO}_{2}$ phase diagram ${ }^{23}$, crystalline $\mathrm{ZrO}_{2}$ coexists with an $\mathrm{SiO}_{2}$-rich liquid phase at temperatures between 1,960 and $2,670 \mathrm{~K}$ for a composition of $\mathrm{ZrSiO}_{4}$. Relatively rapid liquid-phase diffusion can occur in this temperature range. A solid solution of crystalline $\mathrm{SiO}_{2}$ and $\mathrm{ZrO}_{2}$

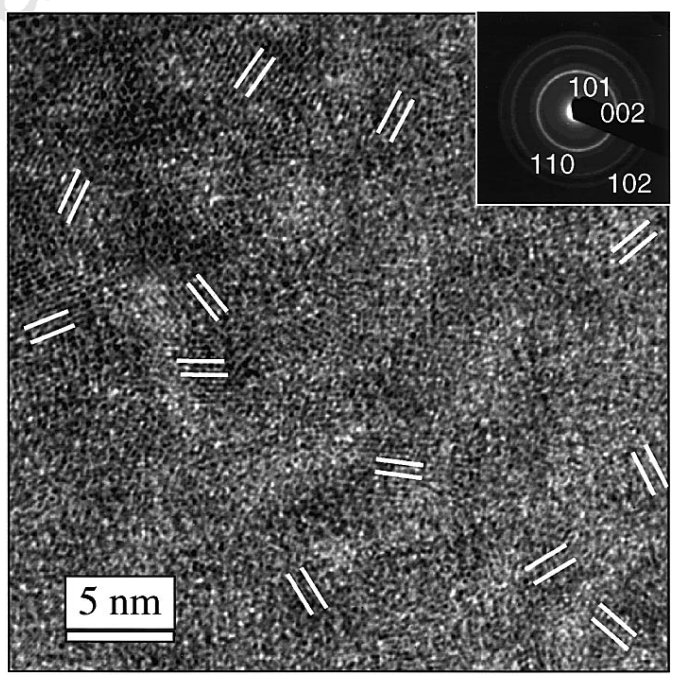

Figure 3 High-resolution TEM image of zircon irradiated at 1,050 K (dose, 3 d.p.a.), showing randomly orientated $\mathrm{ZrO}_{2}$ nanocrystals (highlighted). The corresponding electron-diffraction pattern is given in the inset. Energy dispersive $\mathrm{X}$-ray spectrometry was used to confirm the presence of an amorphous $\mathrm{SiO}_{2}$ component. occurs below the eutectic solidus temperature of $1,960 \mathrm{~K}$ (with correspondingly slower solid-state diffusion parameters), and the solid-state reaction $\mathrm{ZrO}_{2}+\mathrm{SiO}_{2} \rightarrow \mathrm{ZrSiO}_{4}$ occurs at $1,950 \mathrm{~K}$. On the basis of the estimated average kinetic energy for the $\sim 1,000$ atoms contained within the individual displacement cascade regions, the effective temperature should exceed the melting point for zircon. According to the thermal spike model, the relatively high quench rate through the two-phase region (crystalline $\mathrm{ZrO}_{2}$ and $\mathrm{SiO}_{2}$-rich liquid), which occurs for low ambient temperatures, would not allow sufficient time for nucleation of the crystalline $\mathrm{ZrO}_{2}$ phase. However, decreasing the cooling rate at temperatures in the two-phase region between 2,670 and $1,960 \mathrm{~K}$ by increasing the ambient temperature could allow the nucleation of tetragonal $\mathrm{ZrO}_{2}$ in the displacement cascade region.

The $\mathrm{HfO}_{2}-\mathrm{SiO}_{2}$ phase diagram ${ }^{23}$ shows a two-phase region (crystalline $\mathrm{HfO}_{2}$ plus $\mathrm{SiO}_{2}$-rich liquid) from 2,870 to $2,020 \mathrm{~K}$ for a composition of $\mathrm{HfSiO}_{4}$. A peritectic reaction to form hafnon occurs at $2,020 \mathrm{~K}$. The peritectic solidus temperature in hafnon is $63 \mathrm{~K}$ higher than the eutectic solidus temperature in zircon; this temperature difference is close to the difference in minimum irradiation temperatures for the formation of crystalline $\mathrm{HfO}_{2}$ versus $\mathrm{ZrO}_{2}$ crystallites in the displacement cascades of the two materials (1,000 K versus $950 \mathrm{~K}$, respectively).

The published $\mathrm{ThO}_{2}-\mathrm{SiO}_{2}$ phase diagram ${ }^{23}$ shows a two-phase region (crystalline $\mathrm{ThO}_{2}$ plus $\mathrm{SiO}_{2}$-rich liquid) from $\sim 2,470$ to $2,250 \mathrm{~K}$ for a composition of $\mathrm{ThSiO}_{4}$. Thorite is formed by a peritectic reaction with a solidus temperature of $2,250 \mathrm{~K}$. The relatively small temperature range between the liquidus and the solidus, and also the relatively high solidus temperature for thorite compared to hafnon and zircon, are not favourable for the precipitation of $\mathrm{ThO}_{2}$ during cooling of a displacement cascade. Therefore, precipitation of $\mathrm{ThO}_{2}$ in the displacement cascade requires higher ambient temperatures, and the transformation to the component oxides occurs less readily than for the cases of zircon and hafnon.

The irradiation-induced nucleation of new phases in crystalline or amorphous zircon and hafnon is consistent with the concept of thermal spikes. Within the thermal spike model, the temperature in the cascade region is characterized by a cooling rate $\exp (-t / \tau)$, where $t$ is time and the cooling time constant $\tau$ for metals such as nickel with strong electron-phonon coupling is $\sim 1$ ps (refs 24,25 ). As the temperature profile is inversely proportional to the thermal conductivity, and the thermal conductivity of the orthosilicates at $T>1,800 \mathrm{~K}$ is approximately an order of magnitude lower than that of nickel, the cooling time constant for the orthosilicates should be at least $10 \mathrm{ps}$. The magnitude of the diffusion coefficient necessary to produce solute segregation within the displacement cascade region can be estimated to be $D \approx x^{2} / t \approx 1 \times 10^{-8} \mathrm{~m}^{2} \mathrm{~s}^{-1}$ where $x=1.5 \mathrm{~nm}$ is the observed crystallite radius (Fig. 3), the cooling time constant $\tau$ is $10 \mathrm{ps}$, and $t \approx 3 \tau$ is the thermal spike lifetime. This estimate is similar to typical liquid diffusion coefficients ${ }^{26}$.

Crystalline $\mathrm{ZrO}_{2}$ has been observed to precipitate in metamict natural zircons ${ }^{9,10,12}$ and in ion-beam-amorphized zircons heated to $\sim 1,200 \mathrm{~K}$ (ref. 27). Zirconia-rich and silica-rich microdomains were proposed to exist in metamict zircon, evidence for which has recently been obtained by ion microprobe techniques ${ }^{11}$. The present results imply that these domains may form during the cooling of the $\alpha$-recoil cascades in the $\mathrm{U}$ and $\mathrm{Th}$ decay series. $\mathrm{ZrO}_{2}$ - and $\mathrm{SiO}_{2}$-rich 'nanodomains' should occur as fine-scale fluctuations in the amorphous material, and these nanodomains could represent nuclei for the subsequent precipitation of $\mathrm{ZrO}_{2}$ in metamict natural zircons. These fluctuations may lead to a fine-scale redistribution of $U$ and $\mathrm{Pb}$ contained in natural zircon used for geochronology $\mathrm{y}^{28,29}$.

In contrast, irradiation with light ions (for example, $\mathrm{He}^{+}$) does not produce displacement cascades, but instead results in the formation of isolated point defects. So the phase decomposition observed in the present experiments is not expected to occur during irradiation with light ions or as a result of subsequent thermal 
annealing. The use of light ions is, therefore, suggested for the formation of optical waveguides ${ }^{30}$ in zircon.

Received 13 February; accepted 8 June 1998

1. Seitz, F. Radiation effects in solids. Phys. Today 5, 6-9 (1952).

2. Burakov, B. E. et al. in Scientific Basis for Nuclear Waste Management XIX (eds Murphy, W. M. \& Knecht, D. A.) 33-40 (Plenum, New York, 1996).

3. Ewing, R. C. et al. Zircon: A host phase for the disposal of weapons plutonium. J. Mater. Res. 10, 243 246 (1995)

4. Weber, W. J. et al. in Scientific Basis for Nuclear Waste Management XIX (eds Murphy, W. M. \& Knecht, D. A.) 25-32 (Plenum, New York, 1996).

5. Brinkman, J. A. On the nature of radiation damage in metals. J. Appl. Phys. 25, 961-970 (1954).

6. Diaz de la Rubia, T. et al. Molecular dynamics simulation of displacement cascades in $\mathrm{Cu}$ and $\mathrm{Ni}$ : Thermal spike behavior. J. Mater. Res. 4, 579-586 (1989).

7. Wang, S. X. et al. Ion beam-induced amorphization in the $\mathrm{MgO}-\mathrm{Al}_{2} \mathrm{O}_{3}-\mathrm{SiO}_{2}$ system: Part II-An empirical model. J. Non-Cryst. Solids (in the press).

8. Sales, B. C. et al. Structural differences between the glass state and ion-beam-amorphized states of lead pyrophosphate. J. Non-Cryst. Solids 126, 179-193 (1990).

9. Ellsworth, S. et al. Energetics of radiation damage in natural zircon $\left(\mathrm{ZrSiO}_{4}\right)$. Phys. Chem. Mineral. 21, $140-149$ (1994).

10. Farges, F. The structure of metamict zircon: A temperature-dependent EXAFS study. Phys. Chem Mineral. 20, 504-514 (1994).

11. McLaren, A. C. et al. The microstructure of zircon and its influence on the age determination from $\mathrm{Pb} /$ U isotopic ratios measured by ion microprobe. Geochim. Cosmochim. Acta 58, 993-1005 (1994).

12. Vance, E. R. \& Anderson, B. W. Mineral Mag. 38, 605-613 (1972).

13. Weber, W. J. et al. The radiation-induced crystalline-to-amorphous transition in zircon. J. Mater. Res. 9, 688-698 (1994).

14. Keller, C. Untersuchungen über die germanate und silikate des typs $\mathrm{ABO}_{4}$ der vierwertigen elemente thorium bis americium. Nukleonic 5, 41-48 (1963).

15. Correia Neves, J. M. et al. High-hafnium members of the zircon-hafnon series from the granite pegmatites of Zambezia, Mozambique. Contrib. Mineral. Petrol. 48, 73-80 (1974).

16. Speer, J. A. in Reviews in Mineralogy Vol. 5, Orthosilicates (ed. Ribbe, P. H.) 67-132 (Mineralogical Soc. Am. Washington DC, 1982)

17. Ziegler, J. F. Transport and Range of Ions in Matter Version 96.01 (IBM-Research, Yorktown, NY, 1996)

18. Weber, W. J. et al. Radiation effects in crystalline ceramics for the immobilization of high-level nuclear waste and plutonium. J. Mater. Res. (in the press).

19. Abe, H. et al. Amorphization in aluminum oxide induced by ion irradiation. Nucl. Instrum. Meth Phys. Res. B127/128, 170-175 (1997).

20. Meldrum, A. et al. Heavy-ion irradiation effects in the $\mathrm{ABO}_{4}$ orthosilicates: decomposition, amorphization, and recrystallization. Phys. Rev. B (submitted).

21. Heinisch, H. L. \& Singh, B. N. On the structure of irradiation induced collision cascades in metals as a function of recoil energy and crystal structure. Phil. Mag. 67, 407-424 (1993).

22. Bacon, D. J. \& Diaz de la Rubia, T. Molecular dynamics computer simulations of displacement cascades in metals. J. Nucl. Mater. 216, 275-290 (1994).

23. Levin, E. M. \& McMurdie, H. F. Phase Diagrams for Ceramists, 1975 Supplement (Am. Ceramic Soc., Columbus, $\mathrm{OH}, 1975)$.

24. Caro, M. et al. Thermal behavior of radiation damage cascades via the binary collision approximation Comparison with molecular dynamics results. J. Mater. Res. 5, 2652-2657 (1990).

25. Koponen, I. Energy transfer between electrons and ions in dense displacement cascades. Phys. Rev. B 47, 14011-14019 (1993)

26. Kirkaldy, J. S. \& Young, D. J. Diffusion in the Condensed State (Institute of Metals, London, 1987).

27. Weber, W. J. Radiation-induced defects and amorphization in zircon. J. Mater. Res. 5, 2687-2697 (1990)

28. Buick, R. et al. Record of emergent continental crust $\sim 3.5$ billion years ago in the Pilbara craton of Australia. Nature 375, 574-577 (1995)

29. Froude, D. O. et al. Ion microprobe identification of 4,100-4,200 Myr-old terrestrial zircons. Nature 304, 616-618 (1983).

30. Babsail, L. et al. Helium-ion implanted waveguides in zircon. Nucl. Instrum. Meth. Phys. Res. B59/60, 1219-1222 (1991).

Acknowledgements. This work was sponsored by the Division of Materials Sciences, Basic Energy Sciences, and the Environmental Management Sciences Program, US-DOE, with Lockheed Martin Energy Research Corporation.

Correspondence and requests for materials should be addressed to A.M. (e-mail: al-m@worldnet.att.net)

\section{Contribution of hurricanes} to local and global estimates of air-sea exchange of $\mathrm{CO}_{2}$

\section{Nicholas R. Bates* Anthony H. Knap* \\ \& Anthony F. Michaels $\dagger$}

${ }^{\star}$ Bermuda Biological Station For Research, Inc., Ferry Reach, GEO1, Bermuda $\dagger$ Wrigley Institute for Environmental Studies, University of Southern California, Los Angeles, California 90089-0371, USA

The effect of hurricanes on the thermal and physical structure of the upper ocean has been described ${ }^{1}$ but their influence on the ocean carbon cycle and the exchange of carbon between ocean and atmosphere is not well understood. Here we present observations from the Sargasso Sea, before and after hurricane Felix in summer 1995 , that show a short-lived (2-3 weeks) surface seawater cooling of about $4{ }^{\circ} \mathrm{C}$, and a decrease in seawater partial pressure of $\mathrm{CO}_{2}$
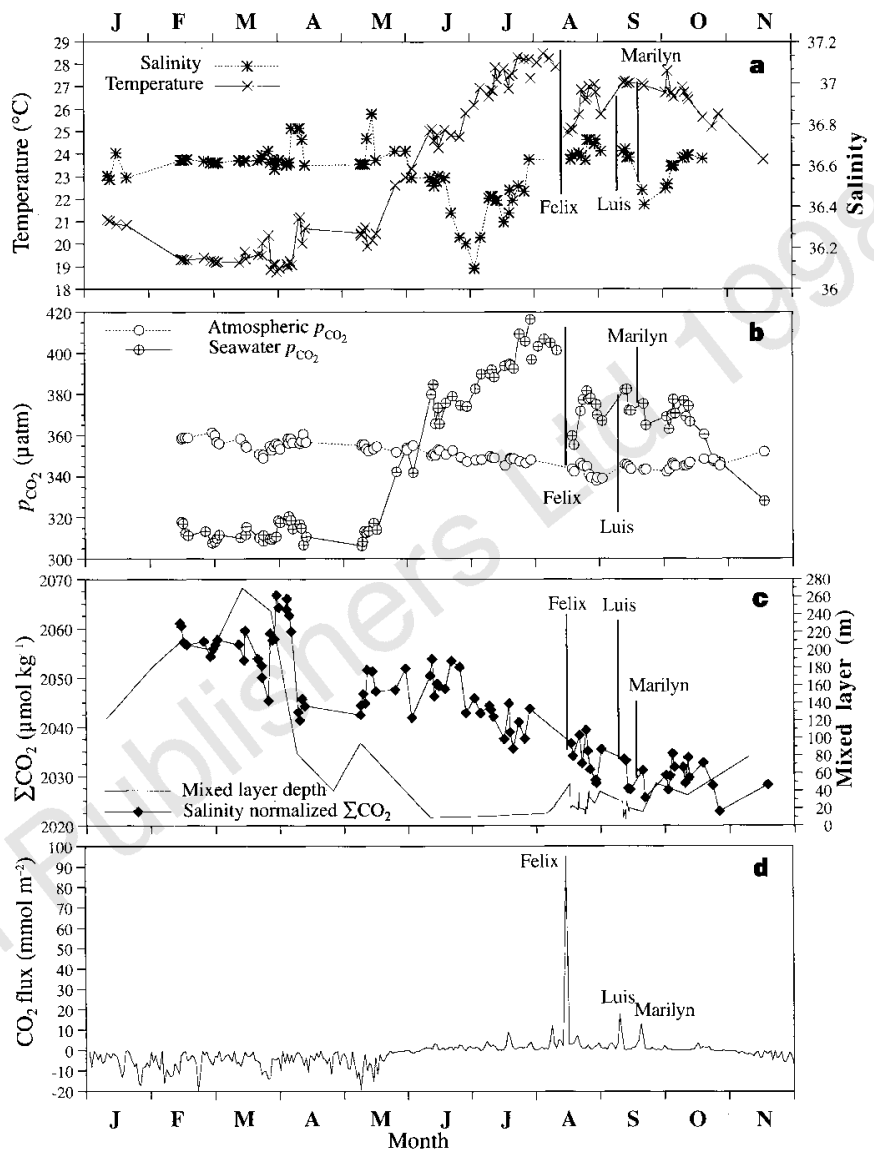

Figure 1 Time-series of surface properties in the Sargasso Sea near Bermuda. Each datum point represents the mean daily value of each property. a, Sea surface temperature and salinity. Thermosalinograph readings of these properties were measured every $10 \mathrm{~s}$ from sea water supplied by the ship's bow intake ( $1.5 \mathrm{~m}$ deep). The last five data points before hurricane Felix represent 3-day averages of sea surface temperature determined by high-resolution AVHRR infrared data. b. Surface seawater and atmospheric $p_{\mathrm{CO}_{2}}$. Surface seawater $p_{\mathrm{CO}_{2}}$ values for the last five data points before hurricane Felix represent 3-day averages of $p_{\mathrm{CO}_{2}}$ calculated from $p_{\mathrm{CO}_{2}}$-temperature relationships observed from June and July. Atmospheric and surface water $p_{\mathrm{CO}_{2}}$ was measured using an automated infrared system (designed by T. Takahashi \& D. W. Chipman, Lamont Doherty Earth Observatory), similar to the gas-chromatographic $p_{\mathrm{CO}_{2}}$ system described in ref. 25. The system alternately analyses dried atmospheric air and air equilibrated with sea water from a 40-I shower-head equilibrator. The measurement was calibrated every 30 minutes with 4 standards of known $\mathrm{CO}_{2}$ content, which have been referenced to World Meteorological Organization (WMO) $\mathrm{CO}_{2}$ standards. The analysis has a precision of better than $\pm 1 \mu$ atm. Surface water $p_{\mathrm{CO}_{2}}$ data was collected at intervals of $\sim 4$ minutes, while atmospheric $p_{\mathrm{CO}}$, was determined every $25 \mathrm{~min}$. Equilibrator temperatures and atmospheric pressure were measured every $2 \mathrm{~min}$. Differences between in situ surface temperature and equilibrator temperatures were $<0.06^{\circ} \mathrm{C}$, requiring no correction to equilibrator $p_{\mathrm{CO}_{2}}$ data. c, Total $\mathrm{CO}_{2}\left(\Sigma \mathrm{CO}_{2}\right)$ normalized to a constant salinity of $36.6\left(\mu \mathrm{mol} \mathrm{kg}^{-1}\right)$ and mixed layer depth $(\mathrm{m}) . \Sigma \mathrm{CO}_{2}$ was calculated from seawater $p_{\mathrm{CO}_{2}}$ and alkalinity using appropriate thermodynamic considerations ${ }^{26,27}$ and dissociation constants ${ }^{28,29} . \mathrm{\Sigma CO}_{2}$ is the total concentration of $\left[\mathrm{HCO}_{3}\right],\left[\mathrm{CO}_{3}\right]$, $\left[\mathrm{CO}_{2}\right]$ and $\left[\mathrm{H}_{2} \mathrm{CO}_{3}\right]$ in seawater. Alkalinity was calculated from salinity as alkalinity was well correlated with salinity in the Sargasso Sea.10. The precision of calculated $\mathrm{\Sigma CO}_{2}$ and alkalinity was $\pm 3 \mu \mathrm{mol} \mathrm{kg}^{-1}$ (N.R.B., unpublished data). d, Daily fluxes of $\mathrm{CO}_{2}$ in the Sargasso Sea. Fluxes were calculated using daily averaged winds and the piston velocity-wind speed relationships of ref. 18. Daily averaged wind speed data was collected in the vicinity of the sampling region at the Bermuda Testbed Mooring ${ }^{15}$ and at the US Naval Air Station on the island of Bermuda (8 $\mathrm{m}$ height). 